\title{
COMMENTS ON THE STANDARD CORD MEASURE OF FOUR FOOT WOOD IN RELATION TO SOLID WOOD CONTENT.
}

\author{
By D. A. SWAN
}

TO MANY who have not dealt with the scaling of pulpwood in relation to the solid wood content of the cord this subject may seem to be of trivial importance. As I go along I will attempt to point out the fallaciousness of this view.

Paradoxically there are many men, in fact companies, that have dealt in pulpwood for years that do not realize what a fluctuating unit the cord is.

Up until about six years ago, at which time I had been cruising pulpwood for four years, a cord of wood was to me simply a pile of four foot bolts containing 128 cubic feet, or its equivalent, solid wood content being generally accepted as being 95 cubic feet for peeled and 85 for rough wood.

In 1930 it was my good fortune to become connected with a progressive paper concern operating in the Adirondacks. Among many things into which they delved in the interests of economical operating and true woods costs, was the solid wood content of the cord.

We tested approximately one per cent. of the total peeled wood cut each year to arrive at an average solid wood content. In 1929 their wood ran in the neighborhood of 84 cubic feet to the cord. In 1933 it was up to 100 cubic feet. Reason, pulp cutters were scarce in 1929 and very independent. It was difficult to make them knot closely and pile properly. In 1933 men were plentiful and close knotting and tight piling could be insisted upon. These figures are based on reliable data, obtained by actually tearing down a number of piles equal to one per cent. of a 25,000 to 30,000 cord cut, and measuring the middle diameter of each stick as well as lengths.

The importance of my subject should be evident now. If for example cost records had been kept on a straight cord basis for those years a comparison would have meant nothing, as the unit in 1933 was $16 \%$ larger than in 1929. However, as many concerns now do, this one converts their cords into cunits each year, using as a converting factor a figure obtained from a test of that year's wood. A "cunit" is simply 100 cubic feet of solid wood. Naturally it is always a fixed unit no matter how the cord may vary. This is the only way that true cost comparisons can be obtained and in these days when costs are all important the expense involved in making an annual 
wood test is well in line with the benefits derived. Actual cost of a one per cent. test should not be over one cent per cord.

There is no logical reason to believe that the case cited is an exceptional one. I have tested individual piles that showed less than 80 cubic feet of solid wood and others that ran as high as 105. Of course, on any one operation in the same type of wood with the same labor conditions and the same management from year to year, solid wood content should not vary greatly, but these conditions are rare in the woods.

It is a popular belief among many pulpwood men that piles of large sized sticks will have a higher solid wood content than piles of small sticks. Actually, as proved by many tests on all sizes of wood, size of sticks has little or nothing to do with it. Piling, knots and crooked sticks are the keys to solid wood content. Theoretically the perfect pile of wood with sticks all the same size and piled one on top of the other contains 100.53 cubic feet, $78.54 \%$ of 128 , the per cent. of a square that is taken up by an inscribed circle. It is rare that a pile will run over that figure and surprising how closely piled wood will approximate it. Of course the greatest solid wood content can be obtained by a combination of large and small sticks and this is the usual woods condition.

Scaling of course is a factor that can tend to keep the cord a fixed unit under various conditions. A standardized system that uses tables for culling out holes lends itself to consistency.

Granting the need of an annual wood test, the question of method arises. Submersion of course is the most accurate but entirely impractical in the woods. Next in accuracy is the laborious method of tearing down a pile and measuring the middle diameter of each stick and length. We followed the latter procedure for a while but superseded it by measuring end diameters on one face of the pile and as many lengths as we could get without disturbing the wood. Thus we got all the diameters, assuming that the end measurements on one face were bound to average between large and small ends, and enough length to give a fair average. This system greatly reduces the field work. Later we hit upon the scheme of graduating a measuring stick in basal areas and recording them instead of inches and fractions. This obviously eliminated considerable office work.

At the suggestion of a Canadian forester whose name I do not recall, we experimented with the following short cut system. A string would be stretched across the face of a pile in any direction but preferably vertically or diagonally from top to bottom, to insure hitting a fair sample of the wood. The 
diameter of each stick that the string passes over is measured and recorded. Their total basal area is computed, and the average diameter of the sticks. The distance between the outside circumferences of the last two sticks touched by the string is measured. Taking this length in feet and multiplying it by the average diameter of the sticks in feet we get an area in square feet. The theory is that the total basal area of the sticks touched by the string bears the same relation to the area computed in square feet as the solid wood content of the pile bears to the scaled dimensions. See figure 1 .

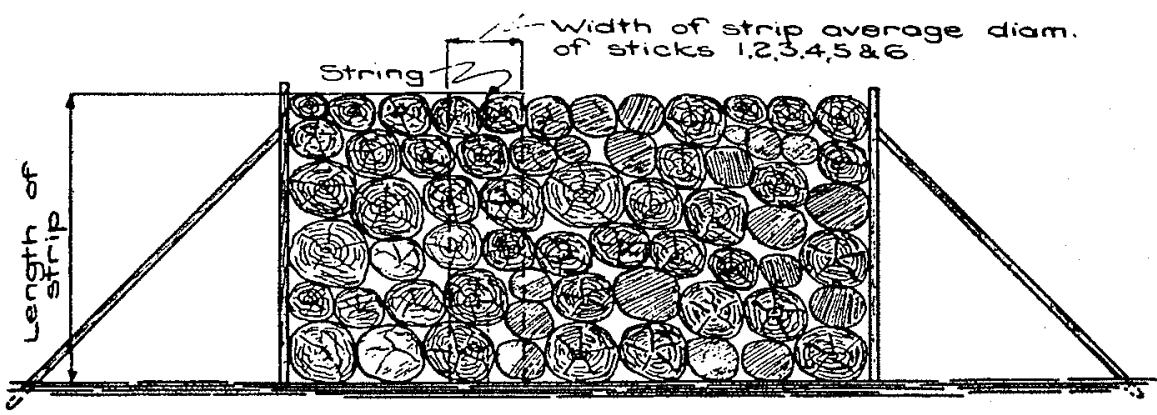

Fig. 1

We checked this method on about 300 cords of peeled wood against our regular $100 \%$ test, taking several samples on each pile. It did not prove consistently accurate enough for our purpose. On most piles it would be within 1 or $2 \%$ but on some it would be away off, although not many were out of reason, and the average for all the piles was within 3 or $4 \%$.

This method can probably not be proved mathematically, but our experience indicated that it is considerably better than no test at all for arriving at a solid wood figure. Its simplicity and rapidity of execution in the field recommend it strongly to pulpwood buyers, etc.

As the importance of this matter is more fully realized undoubtedly some quick, inexpensive and accurate method will be developed. Possibly it could be done cheaply by photography if it were taken up by technicians in that line.

At least it is as worthy of research as many subjects that are being pursued. 